\title{
Prognostic factors in desmoid tumours: an example of translational oncology
}

\author{
Soledad Gallego Melcón
}

$\mathrm{A}^{\mathrm{s}}$ ggressive fibromatosis (AF), also known as desmoid tumour, is a rare tumour consisting of fibroblastic or myofibroblastic clonal proliferation of intermediate malignancy, without the capacity to produce metastasis but with significant local invasiveness. Desmoid tumours are frequently sporadic, but can be seen in familial adenomatous polyposis and familial AF, both identified as being caused by a germline mutation in the adenomatosis polyposis gene (APC).

The mutated $A P C$ gene produces a de-regulation of beta-catenin that contributes to tumorigenesis in desmoid tumours. Beta-catenin is a cadherin-binding protein involved in cell adhesion and in activating transcription when coupled in the nucleus with members of the T-cell factor family of proteins. APC is among the proteins that negatively regulate beta-catenin expression [1]. In sporadic cases, mutations in exon 3 of CTNNB1 (the gene codifying for beta-catenin) are frequently found. These mutations result in stabilisation of beta-catenin and increase in nuclear levels of this protein. This increase produces the transcriptional activation of genes such as $c-M Y C, c-J U N$ and $c y c l i n D$. These mutations appear to be very common in $\mathrm{AF}$ and range from $50 \%$ to $87 \%$ of patients recorded in published series [2]. The type of mutation has an impact on the prognosis of these tumours. Lazar et al. performed CTNNB1 genotyping in a large series of sporadic AF and observed 3 types of mutations in exon 3 (41A, 45F and 45P). Five-year event-free survival was significantly poorer in $45 \mathrm{~F}$-mutated than in 45A-mutated tumours. In this study, abdominal location and young age were also negative prognostic factors [3].

In a recently published CGH array in 194 cases of AF, the authors screened for $A P C$ mutations in patients without CNNTB1 mutations and found, in a small subset of these tumours, 4 recurrent aberrations (6q loss, 5q loss, 20q gains and chromosome 8 gains). Gains in chromosomes 8 and 20 were not associated with an increased risk of recurrence.

S. Gallego Melcón (凶)

Paediatric Oncology

Hospital Universitari Vall d'Hebron

Paseo Vall d'Hebron, 119

ES-08035 Barcelona, Spain

e-mail: sgallego@vhebron.net
In cases with $5 \mathrm{q}$ loss, the minimal common deleted region included the APC gene. Taken together, APC mutations and CNNTB1 mutations, which are mutually exclusive in tumours, may explain tumour generation in $90 \%$ of sporadic cases and in the desmoid tumours found in Gardner's syndrome [4].

Two published gene expression profiles showed frequent overexpression of genes of the Wnt pathway and identified 2 different subsets of tumours that differ in the expression of many extracellular matrix (ECM) genes and probably have different prognosis and behaviour $[5,6]$.

Moreover, desmoid tumours express genes characteristic of mesenchymal stem cells (MSCs). In mice predisposed to desmoid tumours (APC deficient), the number of tumours was proportional to the number of MSCs present in the tumour, suggesting that AF is derived from MSCs [7].

Treatment of AF has been mainly based on surgery and this is the most common initial therapy. There is no controversy regarding treatment of those tumours that can be removed without mutilation or significant disfiguration, such as many of the tumours arising in the lower limbs. The aim of surgery in desmoid tumours is to achieve complete resection; however, even in the case of incomplete resections, tumours can remain stable for a long time, and thus, new surgery or radiotherapy should be reserved for relapses or growing tumours. In unresectable tumours, or when mutilating surgery is foreseen, numerous medical treatments have been proposed. The most common include antioestrogens such as tamoxifen, NSAIDS or, more recently, Cox 2 inhibitors such as sulindac. It is difficult to know the response rates to these therapies, but they could stabilise or induce involution of the tumour in a number of cases. Chemotherapy has been extensively used in unresectable or recurrent tumours, with the most effective combinations being low-dose MTX with vinblastin or vinorelbin [8, 9]. The response rate to this kind of chemotherapy ranges from 30 to $40 \%$ of the cases. More recently, responses to imatinib have been studied and confirmed in a large phase II trial reporting a good response rate [10].

In this issue of Clinical and Translational Oncology, Pajares et al. [11] report the outcome of a short series of patients and correctly point to the use of a multidisci- 
plinary approach for the treatment of AF. In this series, they achieved good local control rates using a combined therapeutic approach consisting in the cautious use of radical surgery, reserving radiotherapy for cases of tumour progression and adding medical treatment for unresectable or progressing tumours.

The clinical course of AF in children may be similar to that in adults. In a recently published paper the completeness of initial resection was the main factor that influenced the frequency of local relapses. Good responses to systemic treatments, and particularly to low-dose chemotherapy, were observed as reported in adults [12].

In conclusion, all these therapeutic modalities should be used in an individualised manner in every patient, including the use of combined treatments to reduce the need of radical surgical approaches. The identification of new prognostic molecular markers could help clinicians in the therapeutic decision-making process.

\section{References}

1. Clevers $H$ (2006) Wnt/beta-catenin signaling in development and disease. Cell 127:469-480

2. Amary MF, Pauwels P, Meulemans E et al (2007) Detection of beta-catenin mutations in paraffinembedded sporadic desmoid-type fibromatosis by mutation-specific restriction enzyme digestion (MSRED): an ancillary diagnostic tool. Am J Surg Pathol 31:1299-1309

3. Lazar AJ, Tuvin D, Hajibashi S et al (2008) Specific mutations in the beta-catenin gene (CTNNB1) correlate with local recurrence in sporadic desmoid tumors. Am J Pathol 173:1518-1527

4. Salas S, Chibon F, Noguchi T et al (2010) Molecular characterization by array comparative genomic hybridization and DNA sequencing of 194 desmoid tumors. Genes Chromosomes Cancer 49:560-568

5. Skubitz KM, Skubitz APN (2004) Gene expression in aggressive fibromatosis. J Lab Clin Med 143:89-98

6. Skubitz KM, Pambuccian S, Manivel JC et al (2008) Identification of heterogeneity among soft tissue sarcomas by gene expression profiles from different tumors. J Translat Med 6:23-35

7. Wu c, Nik-Amini S, Nadesan P et al (2010) Mesenchymal progenitor cells aggressive fibromatosis (desmoid tumor) is derived from mesenchymal progenitor cells. Cancer Res 70:7690-7698

8. Hosalkar HS, Torbert JT, Fox EJ et al (2008) Musculoskeletal desmoid tumors. J Am Acad Orthop Surg 16:188-198
9. Stoeckle E, Coindre JM, Longy M et al (2009) A critical analysis of treatment strategies in desmoid tumours: a review of a series of 106 cases. Eur J Surg Oncol 35:129-134

10. Chugh R, Wathen JK, Patel SR et al (2010) Efficacy of Imatinib in aggressive fibromatosis: results of a phase II multicenter sarcoma alliance for research through collaboration (SARC) trial. Clin Cancer Res 16:4884-4891

11. Pajares B, Torres E, Jiménez B et al (2011) Multimodal treatment of desmoid tumours: the significance of local control. Clin Transl Oncol 13:190194

12. Meazza C, Bisogno, G, Gronchi A et al (2010) Aggressive fibromatosis in children and adolescents. Cancer 116:233-240 